\title{
Economic Reform and Regional Development of Laos
}

\author{
Hatthachan Phimphanthavong \\ Local Development and Global Dynamics, Graduate School in Social Science, University of Trento, Trento, Italy \\ Email: hata.phim@unitn.it
}

Received December 19, 2011; revised February 1, 2012; accepted February 13, 2012

\begin{abstract}
The main purpose of this paper is to identify some reasons behind the economic performance of regions in Laos, especially the impacts of economic transformation from a central-planned economy to market-oriented under New Economic Mechanisms (NEMs) reform in 1986, the impact of reform has pursued significant economic growth, particularly the regional economic performance. Firstly, the growth was faster in big city with better infrastructure and then the growth extension from central to rural region by improving the infrastructure and information network. Moreover, the new policy to open the country leads to increase in the international cooperation and attractive foreign direct investment (FDI). Laos has successfully developed amicable relations with regional states, being a members of many international organization, particularly, a member of ASEAN is necessary for Laos in respect of its economic progress both regional and global procedure.
\end{abstract}

Keywords: Economic Reform; GDP; Regional Development; FDI; Transportation and Growth

\section{Introduction}

Laos is a small landlocked country with an area of 236,800 square kilometers, two-third of which is mountainous (northern); thus, its geographic circumstances constrain both the quantity and quality of agriculture and cause difficulties to the development of trade, social infrastructure, and transportation and communication links. Laos is located in the centre of energetic and prospering regions of Southeast Asia that is endowed with huge potential to support a strategic resource base, and shares borders with five neighboring countries: China, Cambodia, Vietnam, Thailand, and Myanmar. The country is divided into 3 main regions: northern, central, and southern regions. In 2009, the total population of Laos is 6.26 million, major of those live in valleys of the Mekong River and its tributaries, and population density is only 27 per sq. km. Vientiane is the capital and largest city, has about 799,000 residents.

After becoming an independent in 1975, then Laos established the controls over the economy through the centralized fiscal and socialist government until 1985. During that period, the government had seen that the performance of economy was unable to reach the expected goals. Economic management was weak due to the lack of skilled labors, and there was some external assistance, but many projects were not completed at a satisfactory level. In 1986, the new economic reform was initiated, aimed to move expansion from a central-planned economy to market-oriented under NEMs which turned from socialist economic management system into market oriented system. The two basic political goals including: 1) Open Market policy and 2) Introduction of Market economic principles.

Laos has pursued significant economic and institutional reforms aiming at improving social and economic well-being of population by consistently building itself a market-orientated economic. Laos has achieved remarkable economic growth, privatization of former stateowned enterprises, and macroeconomic stability. In addition, it has witnessed a significant rise in public and private investment and improvement of economic activities both regional and global economic cooperation. Those things were contributed to annual average growth rates of over 6 percent per annum from 1990 to 2009 [1]. Moreover, Laos has invited foreign investors and accepted assistance from various governments and organizations around the world, all of these factors are directly effect on economic and regional development of Laos.

This paper aims to identify the situation behind economic performance of Laos, especially to indentify the patterns and analyze some of the drivers of the regional development in Laos after economic reform in 1986. Secondly, it attempts to explain about the impacts of domestic and international market integration on regional development. The comparison analysis is needed to be successful in regional development through domestic and international integration market interest, based on the characteristic of the geographic of the country creating both opportunity and challenge for the creation of the 
new economic system. This paper contributes some information insights into the diverse differences of regions in Laos. The data used in this paper are based on the Lao Expenditure Consumption Survey (LECS), Ministry of Industry and Handicraft in Vientiane, and World Development Indicator (WDI).

This paper consists of four chapters including introductory. Next chapter describes about perspectives of regional development after economic reform, including international cooperation. The third chapter highlights the impact of economic reform on regional development, based on the number of industrial establishments in each region and also the impacts on overall economic development. The last chapter concludes the outcomes and provides suggestions for future development.

\section{Regional Development after Economic Reform}

\subsection{Purposes of Economic Reform}

After getting independent in 1975, the country had followed the socialist system, where the government makes decisions and controls about what to produce, how to produce, and who gets the final product (opposite of that, in a market economy, individuals own property and are free to trade such property and gain from trading property, prices for goods are decided in a free market system where demand dictates what is made). In early 1980s, this system was not satisfied the goal as the economy performance was unable to reach the expected goals, population getting poorer and weak economic system. These issues confirmed that the central-planned system alone is not the most appropriate for Laos, leading to the economic reform.

The transformation from a central-planning to a market oriented economy was launched in 1986, aiming to promote the economic activities that encompassed a variety of evaluates both systemic and macroeconomic characters which are concluded under four main headings: First relates all the characteristic involving in microeconomic view, aiming at improving the structure of intensives and at encouraging the growth of private production. Second is trade liberalization, aiming at promoting the potential of the country based on its specialized advantage and at integrating the country to the international economy particularly in the Southeast Asia. Third is a less accommodating macroeconomic policy in order to secure price stability and reap the growth benefits of economic liberalization. Last one is the legal and institutional measures, which are necessary for the market economy to work $[2,3]$.

Following the introduction of new economic reform, the government of Laos has announced to promote the development of the private sectors, leading to the de- regulated price and production controls, and granted managerial and financial autonomy to state owned enterprises. Under market-oriented economy there are particular discussions of market integration, for example:

- Price liberalization. Complete liberalization except for some key utility prices.

- Agricultural reform. Liberalization of agricultural price, including abolition of the state monopoly for rice marketing.

- Public enterprise reform. Increase autonomy for public enterprises and privatization of selected public enterprises.

- Trade reform. Liberalization of trade through simplification of tariff codes and elimination of most quantitative restrictions.

- Exchange rate reform. Unification of the multiple exchange rate system.

- Foreign investment policy reform, aiming to attract amount of foreign direct investment.

Those reforms are necessary for regional and economic cooperation of Laos, following with the ASEAN and preparing for WTO membership; the reforms have created a less complicated environment for export and import activities and persuaded Laos to become active participants in the world market. However, to achieve higher benefit, the reforms are required to achieve stronger integration with international economy [4].

\subsection{Regional Development and Challenges}

The new characteristic of new economic structure is much different from the central-planned system. It is an opened door policy as to promote the international trade and economic cooperation, particularly with neighboring countries in Southeast Asia as well as the other countries those are interesting to invest in Laos. Since the economic reform was introduced in 1986, the economic development of Laos has showed a strong record of economic growth and poverty alleviation. The performance of economic development had varied significantly across different parts of the country. The rate of economic growth was initially faster in the Mekhong valley, and then during 1990s, the growth has been stronger in northern part [5].

Considering the main idea of the regional development, the government has based on the concept rural development through city extension, by improving transportation network from city to rural. This development concept aims to minimize the gap between regions (North, Center, and South) as bridging the gap among those regions. Based on the idea of Social Economic Development Strategy as following 4 steps of regional developments: 1) Infrastructure improvement as the tip of a spear; 2) Focusing on building village and village development clus- 
ter; 3) Livelihood improvement is at the development core and 4) Welfare upgrading must go one step forward.

The process of regional development is based on the rural development, through the cooperation with national programme [6]:

1) Providing the basic infrastructure system and livelihood improvement in rural areas, in parallel with welfare and healthcare service improvement, reducing the number of poor population in order to achieve the Millennium Development Goals by 2015 as well as to graduate from the list of least developed countries by 2020 .

2) Decreasing the gap between the rural and urban areas, especially in providing permanent resident, and land occupation, basic infrastructure improvement to integrate rural and urban, and in improving living standard and social security consistently, together with maintaining the macroeconomic stability and sustainability. All of these factors must formulate the structure for rural economic development as well as awareness raising for self-sufficient , self-reliant, and self improving development under the party's direction and the government's policy.

3) Ensuring the competence of social economic development integrated with the social development, together with securing the natural resources and environmental conservation that are integrated, harmonized and sustained development from local to central levels.

4) Widening antenatal cooperation and increasing of capacity in mutual aid from countries in the region and foreign countries on the basis of the government's international guidance, etc.

From above development plan, the government's afford alone is not sufficient to achieve those targets. Consequently, the international cooperation is required for this economic performance. For that reason, the regional economic development must promote together the domestic investment and foreign investment. The new economic system as open the country to link with the outside world, leading to the increase in cooperation with international and increase the benefit from regional and international markets [7].

The economic reform has become the most important factor that persuades the economics of Laos has moved to liberalize foreign trade as the open economy through market system; leading to increase the regional economic development and global development. As a landlocked country, so the trade partners started with the neighboring countries, this country has encouraged trade via Vietnam and China to reduce its dependency on Thailand. Meaning that the economic reform has increased in the international competition between 1987 and 1997 as a result of trade liberalization, a main component of NEMs, during this period quantitative restrictions were removed, especially becoming a member of ASEAN in 1997, tar- iffs have been reduced and expected to be reduced further now that Laos is a member of ASEAN, as to meet the requirements of membership in the ASEAN Free Trade Area (AFTA).

The difference in geographic of the country leads to the difference in regional development growth. Based on the data from LECS (1992/1993, 1997/1998, 2002/2003 and 2007/2008) as summary in Table 1, it illustrates some data on the changes in per capita consumption in different regions in Laos.

From data in Table 1, it indicates that the overall growth in consumption was stronger in the beginning of survey from $1992 / 1993$ to $1997 / 1998$. From the late 1990s the growth rate is low due to the impact of financial crisis in Asia. Considering at regional basis, at early 1990s it shows a faster growth in Vientiane capital, which is the richest part of the countries, Central and Southern part of growing slower. In second period (1997/1998 to 2002/2003), the occurring Asian financial crisis are more impact on large regions such Vientiane and Central regions, while South and North regions are the regions to experience higher growth. However, the last survey based on the change from 2002/2003 to 2007/2008, it indicates that the highest growth rate is in Central region where is located close to Vientiane capital, followed by South and North regions, respectively. From this changing, it can confirm the hypothesis of Williamson as the study of Béla Szörfi [8] that the growth comes from the economic strongest area as Vientiane capital and then will distribute to the other region as capital flows from rich to poor regions.

Together with the opportunity of new economic system, there are some constrains and challenges to both international and domestic integration, since Laos has long been vulnerable by limiting natural conditions and very poor infrastructure. Moreover, Laos is a mountainous country with a weakly developed national transport system, the low level of domestic market integration, which is an evident from the large variation in prices of

Table 1. Yearly growth rates of per capita and consumption of households.

\begin{tabular}{|c|c|c|c|}
\hline \multirow{2}{*}{ Regions } & \multicolumn{3}{|c|}{ Comparing LECS I, II, III \& IV } \\
\hline & $\begin{array}{c}1992 / 1993- \\
1997 / 1998\end{array}$ & $\begin{array}{c}1997 / 1998- \\
2002 / 2003 \\
\end{array}$ & $\begin{array}{l}2002 / 2003- \\
2007 / 2008 \\
\end{array}$ \\
\hline North & $2.70 \%$ & $1.20 \%$ & $0.10 \%$ \\
\hline Center & $0.90 \%$ & $0.50 \%$ & $0.60 \%$ \\
\hline South & $1.10 \%$ & $1.70 \%$ & $0.40 \%$ \\
\hline Vientiane Capital & $7.90 \%$ & $-0.40 \%$ & $0.30 \%$ \\
\hline Total Laos & $2.50 \%$ & $0.80 \%$ & $0.35 \%$ \\
\hline
\end{tabular}

Source: Author's calculation based on LECS I, II, III and IV. 
goods and service in more remote locations. Thus, any further trade liberalization as well as further economic reform would eventually push Laos under stresses both political stability and economic challenges. The large investments in transport infrastructure as well as human resource development have to be carried out.

\subsection{International Cooperation}

The government has focused on economic development and how to emerge from the least developed countries by 2020. The international cooperation has shown an important significant role on regional development. It is directed relation to increase of national income and provide more employment opportunity to local people. The question, why the economic reform in Laos is related to international cooperation?

The reform process launched under the umbrella of NEMs, Laos has sought to strengthen international and regional ties. This country is now a member of many regional and international organizations such the Mekong River Commission (MRC), ASEAN, Lao Association of Travel Agency (LATA) and the other international organizations. Moreover, Laos also have received funding from many developed countries and international organizations in case of foreign aids for social and economic development, for example from the International Development Association (IDA) ${ }^{1}$, World Bank, ADB, UNDP, JICA, etc. Applying the study of Hanqin Xue [9], The introduction of new economic policy through openeddoor policy is assumed to contribute in economic development and to improve the appearance of Laos in international environment.

To reach the national development by 2020, one of the most important factors is investment from both domestic investment and FDI, leading to the international cooperation. Thus, the improvement of socio-economic development and foreign economic relations are the main priorities to achieve the objectives, the goals are to combine the NEMs and reinforce conditions for the high economic growth essential for development. We can consider in two sides, on the domestic side, the programme consider to boost domestic production and develop domestic market, while on the international side, it aims to extend international trade and avoid the external trade deficit, by improving the quality of export goods, lifting regulations and mechanisms hampering export-orientated production, improve foreign investment security, boosting transit trade as well as re-export and duty-free zones, and also preparing for AFTA and WTO membership.

In view of increasingly intensifying global competition, the development strategy of each country should be designed to effectively utilize dispersion and agglomeration

${ }^{1}$ ODA is approved by Credit No. 3886-LA/Don No H0840-LA. forces in production and distribution networking. Along the development path, the key issues will start from how to participate in networks, and shift to how to formulate industrial agglomeration, and then how to upgrade industrial structure. Therefore, necessary policy measures differ by country, according to country-specific conditions such as the phase of economic development, factor endowments, and location. In order to intensively investigate the development strategies tailored for the late comers in ASEAN, namely Cambodia, Lao PDR, Myanmar, and Vietnam (CLMV), and ERIA ${ }^{2}$ research project entitled "Development Strategy for CLMV in the Age of Economic Integration” has also been implemented.

\section{The Impacts of Economic Reform}

\subsection{The Impact on Regional Development}

The different in regions of Laos have shown the different impacts of economic reform in terms of economic development and income growth. One indicator, showing the positive impact of new economic introduction, is the significant increase in number of investment. In this case, we have considered the number of industrial establishing in different regions (data from 1995 to 2004). The impact of economic reform and policy adjustment play an important role in encouraging and attracting both domestic and international investments. The industrial establishments are more located in the richer city and trend to grow in the other regions. From the capital city as Vientiane to better condition region as central, followed by southern and northern regions, respectively. The main reason is that the transportation cost which is lower in the big city, the higher transport cost in northern region led to the higher cost for investment as spatial cost variation. The interaction between markets and the distribution of goods for sale in local markets are dependent on both physical transportation networks and transport service providers [10].

The data in Table 2, LECS III, it shows that the average of road access in Laos was only $61.1 \%$ for all seasons, while north region had a lowest number, only $43.3 \%$. In LECS IV, it shows that the average of road access in Laos is significantly increased from $61.1 \%$ to $85.8 \%$, indicating that the government of Laos has invested more budgets for infrastructural improvement because the road access is the key of socio-economic development. Northern region has remarkable improved from $43.3 \%$ to $76.5 \%$ which is higher than in southern region (lowest number), only $74.6 \%$ of road access in both seasons. It is noticeable that only in the capital city (Vientiane) that has the road access for all seasons, follow by the central region which is located closed to Vientiane capital;

${ }^{2}$ ERIA is the Economic Research Institution for ASEAN and East Asia. 
Table 2. Road access characteristic in Laos.

\begin{tabular}{ccccc}
\hline & \multicolumn{2}{c}{$\begin{array}{c}\text { Road Access, share of } \\
\text { villages (\%), 2002/2003 }\end{array}$} & \multicolumn{2}{c}{$\begin{array}{c}\text { Road Access, share of } \\
\text { villages (\%), 2007/2008 }\end{array}$} \\
\hline $\begin{array}{c}\text { Regions } \\
\text { Vientiane }\end{array}$ & Dry Season & All seasons & Dry Season & All seasons \\
Capital & 100.0 & 100.0 & 100.0 & 100.0 \\
Center & 88.2 & 70.2 & 97.7 & 96.5 \\
North & 54.7 & 43.8 & 84.3 & 76.5 \\
South & 77.8 & 61.1 & 83.1 & 74.6 \\
Total Laos & 74.5 & 61.1 & 90.6 & 85.8 \\
\hline
\end{tabular}

Source: The calculation is based on LECS III \& IV, 2002/2003 \& 2007/2008.

therefore, these regions are very attractive for large industrial investment. This is the positive correlation between the transportation network and industrial investment [11]. Moreover, the geographical factors such location, distance to market, road accessibility naturally have a significant impact on the costs of intermediate and final goods [12-14].

To simplify the difference in investment opportunity based on data in Table 3, the variance test made using ANOVA single factor, it shows that there is statistically significant difference (p-value $<0.05$ ) in large industrial investment opportunities among the regions. Considering at the standard deviation, Vientiane capital is 28.74 which is the highest number while in North region only 3.06. This result indicates that the numbers of large industrial investments are more located in big city as Vientiane capital which is the richest city in Laos. This city gets more advantage in terms of transportation system, information network, and human capital. The lower cost of transportation results in the lower cost of investment as well as minimizing the cost for goods distribution to domestic and international markets. Followed by Central region, which is located closed to Vientiane capital be-cause the first priority of government is focusing on urban development and then extension to other regions throughout the countries. These large industries are
Table 3. The large industrial establishment by regions (1994-2004).

\begin{tabular}{cccccccc}
\hline & 1994 & 2000 & 2001 & 2002 & 2003 & 2004 & STED \\
\hline North & 6 & 1 & 5 & 3 & 4 & 10 & 3.06 \\
Center & 22 & 32 & 36 & 38 & 36 & 42 & 6.86 \\
South & 4 & 4 & 13 & 13 & 14 & 25 & 7.78 \\
Vientiane Capital & 57 & 58 & 62 & 58 & 65 & 130 & 28.74 \\
Total & 89 & 95 & 116 & 112 & 119 & 207 & 42.85 \\
$\quad \begin{array}{l}\text { Source of } \\
\text { Variation }\end{array}$ & $S S$ & $d f$ & $M S$ & $F$ & P-value & F crit & \\
Between Groups & 16224.17 & 3 & 5408 & 22.94 & 0.00 & 3.09 & \\
\hline
\end{tabular}

Source: calculation based on the data from Ministry of Industry and Handicraft in Vientiane, Laos, 2005. Notice: The size of industrial establishment is based on the number of employees, it is defined as: small is $<10$, Medium is 10 - 99, and Large is $>99$.

mainly in the manufacturing sectors while some operate in mining, construction and trading sectors.

Considering at the medium size of industrial investment (Table 4), using the same analyses as Table 3 (ANOVA single factor), the result also shows that there is statistically significant difference ( $p$-value $<0.05$ ) in medium investment opportunities among the regions. The highest number of standard deviation is in central region and Vientiane capital which is 69.44 and 48.35, respectively, while the lowest is in southern region which is only 14.86. This result indicates that the number of investment for medium industries are more established in Central region and also Vientiane capital, where there are abundant labour and natural resource as well as better transportation network and geographic, compared to those regions in North and South. The Central region is including cities located in central region are linked to Vientiane capital, along with Mekong river that more attractive for the medium size of investment. Considering the Southern region, it seems to be less industrial establishment because this region already has long experienced and specialized in agricultural products such as

Table 4. The medium industrial establishment by regions (1995-2004).

\begin{tabular}{cccccccc}
\hline & 1994 & 2000 & 2001 & 2002 & 2003 & 2004 & STED \\
\hline North & 69 & 100 & 109 & 97 & 99 & 121 & 17.26 \\
Center & 123 & 183 & 184 & 238 & 227 & 329 & 69.44 \\
South & 82 & 96 & 60 & 88 & 60 & 82 & 14.86 \\
Vientiane Capital & 89 & 133 & 157 & 181 & 228 & 190 & 48.35 \\
Total & 363 & 512 & 510 & 604 & 614 & 722 & 112.37 \\
Source of Variation & $S S$ & $d f$ & $M S$ & $F$ & P-value & F crit & 3.098 \\
Between Groups & 69047.1 & 3 & 23016 & 11.98 & 0.0001 & &
\end{tabular}

Source: calculation based on the data from Ministry of Industry and Handicraft in Vientiane, Laos, 2005. 
green vegetables, fruits, coffee, and rice. Those products from the south are distributed to domestic market and exported to neighboring countries such Thailand [15].

The data in Table 5, the variance test using ANOVA single factor also shows that there is statistically significant difference (p-value $<0.05$ ) in investment opportunities of small businesses among the regions. Even the number of small industries is more established in Central region as the highest value of standard deviation (2437.88), the proportion in the North region is much increased compared with other regions. It is evident that the enterprise structure in the Northern differs from that in other part of Laos, which concentration of smaller enterprises like family business. The fragmentation of market in the northern region that is more appropriate for the geographic of the region as mountainous and the poor infrastructure (transportation). The small business in this region it may also reflect the possibility provided by border trade with neighboring countries, since the northern part of Laos has experienced positive economic development in recent years. The infrastructure is now more improved that linked the trade system with neighbor countries such as China and Thailand.

\subsection{The Impact on Overall Economic Development}

\subsubsection{The Impact on FDI and Trade}

The introduction of market-oriented economy shows the significant growth and more open to international trade and investment. As we have known that Laos is a small and poor country; therefore, the investment from foreign countries in terms of FDI is needed, because FDI plays an important role in job creation, economic growth, capital inflow, and wealth in the host country $[16,17]$. After economic reform, the numbers of FDI and income on international trade have been significant increased. These factors are directly impact on national income as well as GDP growth. From data in Figure 1, it shows that the Laos' trade volume together with the FDI in flows have steadily increased from 1990 to 2009. However, during 2007-2008, we found that the number of FDI was decreased, due to the impact of the world economic crisis. In 2009, the number of FDI was increased again due the world economic is getting in better condition.

For the whole capital inflow of FDI, most ratio of such inflow has gone to be invested mainly in mining and hydropower, for the regional investors have been expressed interest investing in agriculture, agro-processing, and other manufacturing. In agriculture and agro-processing, land-leases have been signed recently for producing pulp from eucalyptus, producing rubber, sugar and palm oil. They involve investors from India, Vietnam, Malaysia, and Thailand.

\subsubsection{The Impact of Reform on GDP}

Laos has emerged into international trade with very deprived social and economic conditions in 1986. Since then, Laos has pursued significant economic and institutional reforms aimed at improving the social and economic well-being of Lao people by consistently building itself a market-orientated economic. The economic reform has witnessed a significant rise in public and private investment and improvement of economic activities, which contributed to average real gross domestic product (GDP) growth rates of over 6\% per annum from 2000 to 2005 (accept in 2001) and over 7\% of annual growth from 2006 to 2009. Moreover, the GDP per capita showed in remarkable growth from US\$303.5 in 2000 to US $\$ 463.5$ in 2005 and to US\$885.7 in 2009 (Table 6).

In order to encourage and maintain high economic growth, several policy changes since beginning of year 2004. In late of the same year, Laos aimed Normal Trade Relations status with the US, allowing Laos-based producers to benefit from lower tariffs on exports. This means that Laos has a good opportunity to take the steps to join the World Trade Organization (WTO). We can say that the resulting of trade policy reforms would im-

Table 5. The large industrial establishment by regions (1994-2004).

\begin{tabular}{|c|c|c|c|c|c|c|c|}
\hline & 1994 & 2000 & 2001 & 2002 & 2003 & 2004 & STED \\
\hline North & 3653 & 6952 & 9648 & 8188 & 8262 & 7990 & 2049.00 \\
\hline South & 1786 & 3257 & 4574 & 4205 & 4603 & 5156 & 1224.42 \\
\hline Vientiane Capital & 639 & 1525 & 1750 & 1810 & 1870 & 1465 & 455.651 \\
\hline Total & 10374 & 20952 & 26684 & 24026 & 24874 & 25271 & 5496.37 \\
\hline Source of Variation & SS & $d f$ & MS & $F$ & P-value & F crit & \\
\hline Between Groups & 212657034.1 & 3 & 70885678 & 23.93 & 0.00 & 3.098 & \\
\hline
\end{tabular}

Source: calculation based on the data from Ministry of Industry and Handicraft in Vientiane, Laos, 2005. 
prove the business environment, which would be more attractive for domestic as well as foreign investments, since this factor is one of the key factors influences in economic development.

Considering at the growth in the share of GDP in each sector based on the value added of each sector, it shows that economic development of Laos is still highly dependent on natural resources, mainly from agricultural sector. Even though both industrial and service sectors have experienced a high rate of growth while agriculture share of GDP has become lower and lower in previous years, the agriculture still accounts for the largest share of GDP; it accounts for more than 50 percent of the GDP share in 2000 and less than 40 percent in 2009 (Figure 2).

In long term, even, the agricultural sector would have a strong, positive and significant influence on economic growth, whereas over the extended period, the industrial sector as well as service sector tends to be more dominant in the GDP growth. In 2009, the share of value added in industrial sector is almost equivalent to the share of agricultural sector.

The above figure shows that the industrial value-added in the share of GDP has slowly been increasing, particularly since 1986 when the policy for FDI was improved (Decree No. 73/PM) to attract more investors. The growth in industrial sector is based on the modest growth in the manufacturing subsectors, accounting for over 75 percent of industry sector, especially in the garment industry, a principal manufacturing export as one of the three large export earners of Laos government, together with timber and electricity products. Moreover, it is projected to increase, based on the improved prospects in the international market, particularly in the European markets. In this case, Laos would benefit from a rise in the regional demand from neighboring countries, especially from the Thai economy, which leads to the possibility of obtaining normal trading associates with the United States (US). This would transform into significant potential for growth in manufacturing in the medium term.

\section{Conclusion and Policy Implication}

\subsection{Conclusions}

This paper has aimed to identify the impact of economic reform on economic development of Laos, particularly, the pattern of regional development since the characteristic of each region is different in term of geographic. After introduction the new economic policy, Laos has pursued significant economic and institutional reforms aiming at improving social and economic well-being of Laos people by consistently building itself a market-orientated economic. From the early 1990s, it has invited foreign investors and accepted assistance from various governments and organization around the world. The positive reform is the basic for considerable rapid economic growth throughout the 1990s to early 2000s, the improvement of international relationship leading to the increasing of trading partner as well as increasing the number of foreign investment. Those factors influence in

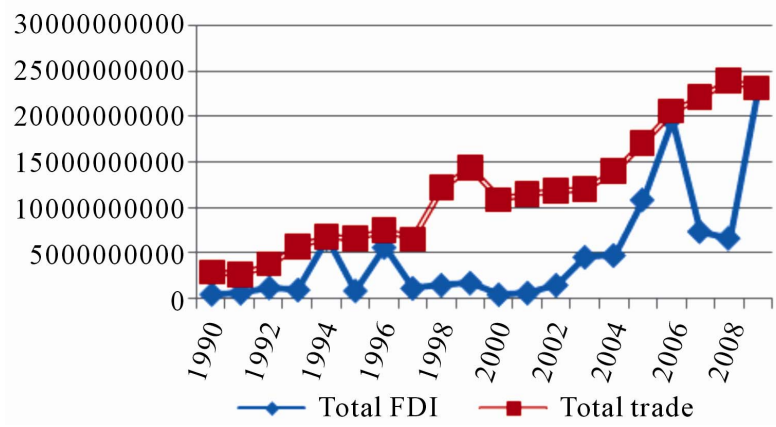

Figure 1. Total trade and FDI inflows since 1990 (US dollars constant of year 2000). Source: Data Analysis based on World Development Indicator 2010.

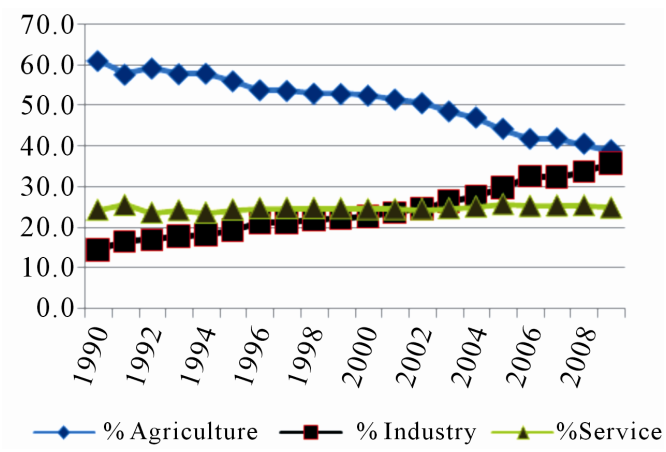

Figure 2. The impact on GDP shared 1990-2009 (US dollars constant of year 2000). Source: Author calculated based on World Database Indicator 2011.

Table 6. Economic indicators and population of Laos, 1990-2009.

\begin{tabular}{cccccccccccc}
\hline & 1990 & 2000 & 2001 & 2002 & 2003 & 2004 & 2005 & 2006 & 2007 & 2009 & 2009 \\
\hline Growth (\%) & 6.69 & 6.32 & 4.62 & 6.87 & 6.21 & 7.02 & 6.77 & 8.65 & 7.84 & 7.79 & 7.59 \\
GDP per capita (US\$) & 152.0 & 303.5 & 303.9 & 314.0 & 355.7 & 410.9 & 463.5 & 595.7 & 693.6 & 856.2 & 885.7 \\
Population (Million) & 4.21 & 5.40 & 5.50 & 5.58 & 5.65 & 5.75 & 5.84 & 5.93 & 6.04 & 6.15 & 6.26 \\
\hline
\end{tabular}

Source: Laos’ Economic Statistics and Indicators from Economy Watch and $\mathrm{PWT}^{3}$ 7.0.

${ }^{3}$ PWT is Penn World Table. 
economic development as increase in GDP and play a role in emerging the country from least developed countries by 2020 .

This paper shows that at the beginning of reform the strongest growth occurred in the big region such Vientiane capital, where is the richest areas with better infrastructure, followed by the Central region where is located close to capital city, then faster growth was found in South and North regions. Looking at large industrial investment as well as the medium size industries mostly located in the urban region and then extended to the other region such North and South regions when the transportation systems have been improved.

\subsection{Political Implication}

The different in geographic and infrastructure in each region, caused diverse patterns of regional development in Laos. Those facts are become the challenges for the government. Thus, the first priority is to improve the transportation and information system through the country especially in rural areas where there are abundant in terms of natural resources. If the transportation is improved, it would attract more investment in rural region that would benefit for the all regions in the country.

Second, as to support the transformation for seeking new markets and new investors, the investment policy issues especially the one door policy for foreign investors should be developed and published as to reduce the time for negotiation between government and foreign investors and also to avoid the corruption through document procedure. Liberalization and the "open door" policies should be further implemented to enhance the competitiveness of Laos' products and Laos' economy in international community. The last suggestion is human resource improvement, since the integration international cooperation, the qualified staffs are required for the international discussing as well as working with international organizations.

\section{REFERENCES}

[1] World Bank, "Sustaining Growth Coping With Rising Uncertainty,” World Bank Report, Vientiane Capital, 2011.

[2] P. Murrel, "Can Neoclassical Economics Underpin the Reform of Centrally Planned Economies?” Journal of Economic Perspectives, Vol. 5, No. 4, 1991, pp. 59-76.

[3] G. Hodgson, “The Approach of Institutional Economics,”
Journal of Economic Literature, Vol. 36, No. 1. 1998, pp. 166-192.

[4] Y. Bourdet, "The Economics of Transition in Laos: From Socialism to ASEAN Integration," ASEAN Economic Bulletin, Singapore City, 2000.

[5] M. Anderson, A. Engvall and A. Kokko, "Regional Development in the Lao PDR,” Country Economic Report, SIDA, 2007.

http://www.sida.se/Documents/Import/pdf/Regional-Deve lopment-in-the-Lao-PDR.pdf

[6] NLBRPA, "Rural Development and Poverty Alleviation," National Five-Year Plan for Rural Development and Poverty Alleviation of Laos, Prime Minister Office, 2010.

[7] IMF, "National Growth and Poverty Eradication Strategy (NGPES),” IMF, Washington DC, 2004. http://www.imf.org/external/pubs/ft/scr/2004/cr04393.pdf

[8] S. Béla, "Development and Regional Disparities: Testing the Williamson Curve Hypothesis in the European Union,” Focus on European Economic Integration, No. 2, 2007, pp. 100-121.

[9] H. Q. Xue, "China's Open Policy and International Law," Chinese Journal of International Law, Vol. 4, No. 1, 2005, pp. 133-139. doi:10.1093/chinesejil/jmi004

[10] M. Anderson, A. Engvall and A. Kokko, "Regional Development in Laos. Growth Patterns and Market Integration,” Working Paper, Stockholm School of Economics, Stockholm, 2007.

[11] R. Ahmed and M. Hossain, "Developmental Impact of Rural Infrastructure in Bangladesh,” Research Report, International Food Policy Research Institute (IFPRI), 1990.

[12] E. M. Hoover, "The Location of Economic Activity," McGraw Hill Book Company Inc., New York, 1948.

[13] W. K. D. Davies, "Geography of Market Centers and Retail Distribution,” Progress in Human Geography, Vol. 16, No. 2, 1992, pp. 219-222. doi:10.1177/030913259201600204

[14] E. M. Gramlich, "Infrastructure Investments: A Review Essay,” Journal of Economic Literature, Vol. 32, No. 3, 1994, pp. 1176-1196

[15] B. Sisouphanthong and C. Taillard, “Altlas of LaosSpatial Structure of the Economic and Social Development of Laos,” Silkworm Book, Chiang Mai, 2000.

[16] S. Fredrik and O. Yumiko, "FDI and the Dynamics of Productivity in Indonesian Manufacturing," Journal of Development Studies, Vol. 41, No. 1, 2005, pp. 160-182. doi:10.1080/0022038042000276608

[17] N. T. Xuan and Y. Xing, "Foreign Direct Investment and Exports: The Experience of Vietnam,” Economy of Transition, SSRN eLibrary, Vol. 16, No. 2, 2008, pp. 183-197. 